\title{
The significant factors for the people with epilepsy high employability based on multiple intelligence scores
}

\author{
Nur Sofia Nabila Binti Alimin ${ }^{a}$, Siti Rahmah Awang, ${ }^{c, *}$ \\ ${ }^{a}$ Faculty of Management, Universiti Teknologi Malaysia, 81310 UTM Johor Bahru, Johor, Malaysia. \\ ${ }^{b}$ Department of Human Resource Development, Faculty of Management, Universiti Teknologi Malaysia, 81310 UTM Johor Bahru, Johor, Malaysia \\ *Corresponding Author: atieawang@hotmail.com
}

\section{Article history :}

Received 23 December 2015

Accepted 3 January 2016

GRAPHICAL ABSTRACT

\begin{abstract}
The objective of this study is to develop an employability model which involves significant factors that lead to high employability for People with Epilepsy (PWE). The sample used in this study consists of outpatients at the Neurology Department Hospital Kuala Lumpur (HKL) and Hospital Sultanah Aminah (HSA), Johor Bahru. The sample size from HKL are 148 patients and from HSA are 67 patients that made up a total sample of 215 patients. The main method used in this study is binary logistic regression analysis in order to build the model and to determine the significant employability factors. Several model fit tests like Classification Table, Omnibus Tests of Model Coefficients, Likelihood-Ratio Test, Hosmer and Lemeshow Test and Cox and Snell $\mathrm{R}^{2} \&$ Nagelkerke $\mathrm{R}^{2}$ are discussed in this paper. From the employability model built, eleven significant factors are obtained which increase the chances for the PWE to be employed namely gender, marital status, education background, age of the respondents, onset age, musical intelligence, kinesthetic intelligence, logic/math intelligence, spatial intelligence, intrapersonal intelligence and naturalistic intelligence.
\end{abstract}

Keywords: People with Epilepsy, Employability Model, Multiple Intelligence, Logistic Regression Analysis

(C) 2016 Penerbit UTM Press. All rights reserved http://dx.doi.org/10.11113/mjfas.v12n1.345

\section{INTRODUCTION}

Epilepsy is one of the common chronic serious neurological diseases that affect approximately 50 million individuals [1]. Epilepsy is a term given for syndromes of epileptic seizures. An epileptic seizure is a disorder of the nervous system in which abnormal electrical activity in the brain causes a seizure [2]. However, although epilepsy can be related to the brain, it has no correlation with the individual intelligence [3].

Seeking an employment is one of the main problems faced by the people who living with epilepsy. In the previous researches, epilepsy is associated with high expected rates of unemployment and underemployment. For example, a survey conducted in the United States revealed that 25\% PWE were unemployed as compared with $5 \%$ of the overall population. Similarly, in the United Kingdom, the unemployment rate was $46 \%$ among PWE as contrasting to $19 \%$ in the general population [4].

The aim of this study is to build an employability model. A psychometric test called Ability Test in Epilepsy (ATIE) ${ }^{\circ} 2008$ [8] was used to develop the profiles of the PWE and then a logistic regression was applied to build the model that was based on the Howard Gardner's Multiple Intelligence (MI) theory [5]. This study discusses the major problems that were faced by PWE to get and to retain their job. Based on previous research by Lim et al., [6], the percentage of the unemployment rate for PWE in Neurology Clinic and Ward at the University of Malaya Medical Centre, Malaysia was $27 \%(n=250)$ which was considered high [6]. Therefore, it could be concluded that unemployment problem is an issue to the PWE.

Several studies also confirmed the unemployment and underemployment rates are generally higher for PWE as compared to general population [7]. PWE also has been known to have significant problem related to their employment for more than three decades. As example, PWE experience objective boundaries such as those related to driving or working in situations in which they may be open up for injury [7].

A way to help the PWE identifies their capability and capacity in finding jobs is by using measuring instruments or tools. One of the ways it can be performed is by using psychometric tests. This psychometric test refers to the testing done to individuals in order to measure their competency in a specific area of functioning. In this study, a psychometric test namely, $\operatorname{ATIE}^{{ }^{O}} 2008$ [8] is used to identify the level of intelligence that the PWE possess and 
also to help in building an employability model that revealed the significant factors for them in getting engaged with a job.

\section{METHODOLOGY}

\subsection{Subjects}

The data used in this study is a secondary data obtained from [8] previous work. The study was conducted in two different hospitals which are Hospital Kuala Lumpur (HKL) and Hospital Sultanah Aminah (HSA).

\subsection{Instrument}

The main instrument used in this study is a psychometric test called Ability Test in Epilepsy, ATIE $^{\odot}$ [8], which was developed based on Gardner's Multiple Intelligence theory that comprises of eight intelligences. This instrument measured the total scores of multiple intelligences possessed by PWE which are divided into eight types namely musical, bodily/kinesthetic, math/logic, spatial, linguistic, interpersonal, intrapersonal and naturalist.

The psychometric test was divided into nine parts. The first part is about demographic profiles of the respondents and the illness background. The next eight parts are the respondent's intelligence profiles which consist of 11 items for musical intelligence and 10 items for the other seven intelligences [7]. The summary of the parts can be seen in the Table 1 .

Table 1 Summary of the Psychometric Test

\begin{tabular}{ccc}
\hline Part & Item & $\begin{array}{c}\text { Number of } \\
\text { Items }\end{array}$ \\
\hline 1 & $\begin{array}{c}\text { Demographic } \\
\text { Information } \\
\text { Information on } \\
1\end{array}$ & 15 \\
\hline 2 & illness & 3 \\
3 & Musical & 11 \\
4 & Bodily Kinesthetic & 10 \\
5 & Math/Logic & 10 \\
6 & Spatial & 10 \\
7 & Linguistic & 10 \\
8 & Interpersonal & 10 \\
9 & Intrapersonal & 10 \\
Source: Ability Test in Epilepsy, Awang $(2012)$
\end{tabular}

\subsection{Logistic Regression Analysis}

Logistic regression is sometimes called the logistic model or logit model. It analyzes the relationship between multiple independent variables and a categorical dependent variable and also estimates the probability of occurrence of an event by fitting data to a logistic curve [10]. For this study, the event is the probability for the occurrence of the
PWE being employed or not employed. Logistic regression can be divided into two models which are binary logistic regression and multinomial logistic regression. But, in this study a binary logistic regression will be applied.

\section{RESULTS AND DISCUSSION}

\subsection{Model Fit Tests}

\subsubsection{Classification Table}

Table 2 shows the overall percentage of correctly classified cases which is $92 \%$. This means that this table shows $92 \%$ of the overall data have been classified by the model. Therefore, based on this value, it can be assumed that all respondents were correctly predicted to be employed. From this table, the sensitivity and specificity of the model can also be identified. The sensitivity of the model can be seen when it is able to correctly classify the percentages for the PWE who were employed (95.3\%) and unemployed (81.5\%). However, this assumptions need further testing to improve its accuracy [11].

Table 2 Classification Table

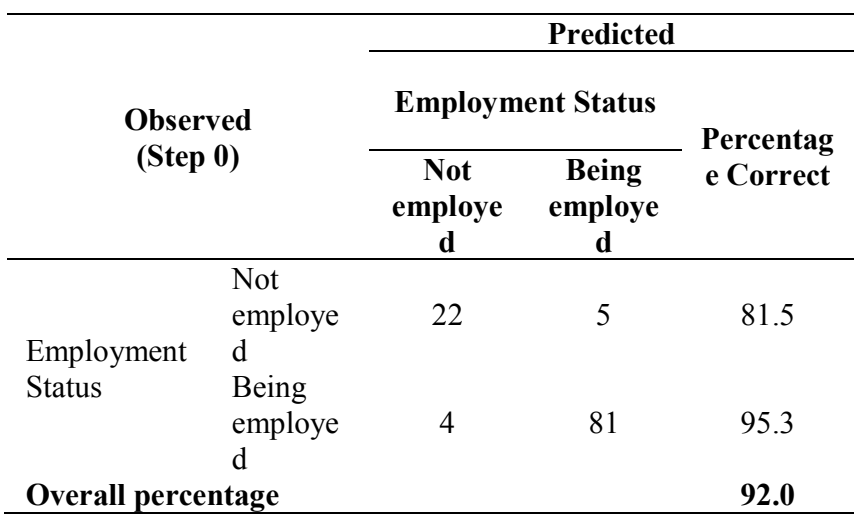

\subsubsection{Omnibus Tests of Model Coefficients}

These tests give an overall indication of how well the models performed to support the assumption given in previous Classification Table. This is also referred to as a 'goodness of fit test'. Table 3 shows the significant values that determine the usefulness of the developed model. In addition, it also supports the previous assumptions that $95.3 \%$ of respondents would be employed.

Based on Pallant (2010), if the significance value (sig-val) is $<0.05$, the model is better than the previous assumption shown in Table 2. Table 3 shows that all the $p$ values for all tests are $=0.0001$ which are $<0.05$ and the chi-square value is 79.35 with 26 degree of freedom (df). The results indicate that the model can be used and supports the assumption that all respondents would be employed $\left(\chi^{2}=79.35, \mathrm{df}=26, p<0.05\right)[12]$. 
Table 6 Changes in -2LL

Table 3 Omnibus Tests of Model Coefficients

\begin{tabular}{lllll}
\hline Tests & & $\begin{array}{l}\text { Chi- } \\
\text { square }\end{array}$ & df & $\boldsymbol{p}$-value \\
\hline \multirow{2}{*}{ Step 1 } & Step & 79.345 & 26 & 0.0001 \\
& Block & 79.345 & 26 & 0.0001 \\
& Model & 79.345 & 26 & 0.0001 \\
\hline
\end{tabular}

\subsubsection{Likelihood-Ratio Test}

In order to test the null hypothesis as stated below, the difference between -2LL for the complete model and 2LL for the constant-only model must be found. Table 4 shows that the value of -2LL for constant-only model is 123.718 and that the value of -2LL for full model is 44.373 as shown in Table 5. Thus, the difference of these two constant is 79.345 which is shown in Table 6. These findings can also be supported by the $p$-value in Table 6 that is 0.0001 . Therefore, it can be concluded that all of the coefficients in the model are not 0 and the model is useful [11].

$$
\begin{aligned}
& \mathrm{H}_{\mathrm{o}}: \beta_{\mathrm{i}}=0 \\
& \mathrm{H}_{\mathrm{a}}: \beta_{\mathrm{i}} \neq 0
\end{aligned}
$$

Table 4 Constant-Only Model

\begin{tabular}{cc}
\hline Iteration & $\mathbf{- 2}$ Log Likelihood (-2LL) \\
\hline 1 & 123.976 \\
2 & 123.718 \\
3 & 123.718 \\
4 & 123.718 \\
\hline Initial -2LL & $\mathbf{1 2 3 . 7 1 8}$ \\
\hline
\end{tabular}

Table 5 Full Model

\begin{tabular}{cc}
\hline Step & -2 Log Likelihood (-2LL) \\
\hline 1 & 44.373 \\
\hline
\end{tabular}

\begin{tabular}{llll}
\hline Tests & Chi-square & df & $\boldsymbol{p}$-value \\
\hline Step & 79.345 & 26 & 0.0001 \\
Block & 79.345 & 26 & 0.0001 \\
Model & 79.345 & 26 & 0.0001 \\
\hline
\end{tabular}

\subsubsection{Hosmer and Lemeshow Test}

Hosmer and Lemeshow Test is the most reliable test of model fit in which can be interpreted differently from the omnibus test. To support the model built in this study, the $p$-value must be greater than 0.05 [12]. The $p$ value shown in Table 7 is $0.876(p>0.05)$ which indicates that the model built has good model fit.

Table 7 Hosmer and Lemeshow Test

\begin{tabular}{ccc}
\hline Chi-square & df & $\boldsymbol{p}$-value \\
\hline 3.78 & 8 & 0.876
\end{tabular}

\subsubsection{Cox and Snell $R^{2} \&$ Nagelkerke $R^{2}$}

These tests give information about the usefulness of the model. The Cox and Snell R Square and the Nagelkerke R Square values provide an indication of the amount of variation in the dependent variable explained by the model [12]. Table 8 shows that the value of Cox \& Snell R Square is 0.51 and Nagelkerke R Square is 0.76 suggesting that $51 \%$ and $76 \%$ which is half and more than half of the variation in the outcome variable respectively, can be explained by the logistic regression model. Therefore, the Nagelkerke $\mathrm{R}$ Square test was more acceptable and preferable for the model built as it shows more than half of the overall data $(76 \%)$ were represented in the model.

Table 8 Model Summary

\begin{tabular}{cc}
\hline Cox \& Snell R Square & Nagelkerke R Square \\
\hline 0.51 & 0.76
\end{tabular}

\subsection{Employability Model}

Based on the results from the Wald test, this employability model was built. This main employability model consists of only the significant factors that increase the probability for the PWE to be employed. There are eleven significant 
factors which include four categories from demographic profiles, one factor from illness background and six categories of intelligence profiles namely gender, marital status, category of education, age of the respondents, onset age, musical intelligence, kinesthetic intelligence, logic/math intelligence, spatial intelligence, intrapersonal and naturalistic intelligence.

$$
\begin{aligned}
\mathbf{Z}_{\mathrm{e}}= & -8.627 * \mathrm{G}_{1}+8.960 * \mathrm{~S}_{1}+12.972 * \mathrm{Ed}+18.035 * \\
& \mathrm{Ed}_{2}-0.285 * \mathrm{~A}_{1}-0.229 * \mathrm{~A}_{2}+3.101 * \mathrm{X}_{\mathrm{mu2}}+2.892 \\
& * \mathrm{X}_{\mathrm{k} 1}-4.074 * \mathrm{X}_{\mathrm{k} 2}-3.767 * \mathrm{X}_{\mathrm{ma} 1}+4.983 * \mathrm{X}_{\mathrm{s} 2}- \\
& 6.676 * \mathrm{X}_{\mathrm{ia} 1}+2.450 * \mathrm{X}_{\mathrm{n} 1}
\end{aligned}
$$

where

$\begin{array}{lll}\mathrm{G}_{1} & = & \text { Gender (Males) } \\ \mathrm{S}_{1} & = & \text { Marital Status (1) } \\ \mathrm{Ed}_{1} & = & \text { Education Background (1) } \\ \mathrm{Ed}_{2} & = & \text { Education Background (2) } \\ \mathrm{A}_{1} & = & \text { Age } \\ \mathrm{A}_{2} & = & \text { Onset age } \\ \mathrm{X}_{\mathrm{m} 2} & = & \text { Musical intelligence (2) } \\ \mathrm{X}_{\mathrm{k} 1} & = & \text { Kinesthetic intelligence (1) } \\ \mathrm{X}_{\mathrm{k} 2} & = & \text { Kinesthetic intelligence (2) } \\ \mathrm{X}_{\mathrm{ma} 1} & = & \text { Mathematical intelligence (1) } \\ \mathrm{X}_{\mathrm{s} 2} & = & \text { Spatial intelligence (2) } \\ \mathrm{X}_{\mathrm{n} 1} & = & \text { Naturalistic intelligence (1) } \\ \mathrm{X}_{\mathrm{ia} 1} & = & \text { Intrapersonal intelligence (1) }\end{array}$

\subsubsection{Predicted Probabilities for the PWE's Employment Status}

In this section, the probability of $\mathrm{P}(\mathrm{Y}=1)$ will be calculated based on different values of independent variables $(\beta i)$. The calculation for the predicted probabilities for the PWE employment status can be calculated as below. The calculations will involve examples of two PWE. The model used to calculate the predicted probability is the employability model $\left(Z_{\mathrm{e}}\right)$ obtained from the logistic regression analysis.

Based on the model, the probability for the PWE to be employed can be calculated as presented below where the value of $Z_{\mathrm{e}}$ is substituted in equation (1.2).

$$
\mathrm{P}(\mathrm{Y}=1)=\frac{1}{1+e^{-Z e}}
$$

where $\mathrm{P}(\mathrm{Y}=1)$ is probability of the PWE to be employed.

If the calculated probability of employment status is $\geq$ 0.5 , then we can say that the PWE is likely to be employed. If the probability of employment status is $\leq 0.5$, the PWE is likely to be unemployed. For example if, the demographic profiles, illness background and intelligence profiles for the PWE have the following values as described in Table 9.
Table 9 Summary of Example of Characteristics of PWE

\begin{tabular}{ccc}
\hline Variables & Label & Values \\
\hline $\mathrm{G}_{1}$ & Female & 1 \\
$\mathrm{~S}_{1}$ & Single & 0 \\
$\mathrm{Ed}_{1}$ & College & 2 \\
$\mathrm{Ed}_{2}$ & Age & 25 \\
$\mathrm{~A}_{1}$ & Onset age & 5 \\
$\mathrm{~A}_{2}$ & Mediocre & 1 \\
$\mathrm{X}_{\mathrm{mu} 2}$ & - & - \\
$\mathrm{X}_{\mathrm{k} 1}$ & High & 2 \\
$\mathrm{X}_{\mathrm{k} 2}$ & High & 2 \\
$\mathrm{X}_{\mathrm{ma} 1}$ & Mediocre & 1 \\
$\mathrm{X}_{\mathrm{s} 2}$ & High & 2 \\
$\mathrm{X}_{\mathrm{n} 1}$ & Mediocre & 1 \\
$\mathrm{X}_{\mathrm{ia} 1}$ & 0.85 \\
\hline $\mathrm{P}(\mathrm{E})$ & \multicolumn{2}{c}{ Employed } \\
\hline Employment Status & \multicolumn{2}{c}{} \\
\hline
\end{tabular}

The calculation for the example can be calculated as below:

1) Substituting all the characteristics value in Table 9 into equation (1)

$$
\begin{aligned}
\mathrm{Z}_{\mathrm{e}}= & -8.627+18.035 *(2)-0.285 *(25)-0.229 *(5) \\
& +3.101 *(1)-4.074 *(2)-3.767 *(2)+4.983 * \\
& (1)-6.676 *(1)+2.450 *(2) \\
\mathrm{Z}_{\mathrm{e}}= & 1.715
\end{aligned}
$$

2) Substitute the value $Z_{e}$ into equation (2)

$$
\mathrm{P}(\mathrm{Y}=1)=\frac{1}{1+e^{-1.715}}=0.85
$$

The results shows that the PWE is more likely to be employed with the $\mathrm{P}(\mathrm{Y})=0.85$.

\section{CONCLUSION}

As a conclusion, elevens significant factors were found to be related to PWE employment status which are gender, marital status, category of education, age of the respondents during answering the questionnaire, onset age, musical intelligence, kinesthetic intelligence, logic/math intelligence, spatial intelligence, intrapersonal and naturalistic intelligence.

\section{ACKNOWLEDGEMENT}

The authors gratefully acknowledge the financial support from Universiti Teknologi Malaysia research grant (Vote 00K55). 


\section{REFERENCES}

[1] Lim, S. K., Wo, S. W., Wong, M. H., Tan, C. T. (2013). Impact of epilepsy on employment in Malaysia. Epilepsy \&Behaviour. 27, 130-134.

[2] Schmidtand, R. F., and Willis, W. D. (2007). Encyclopedia of Pain. Springer-Verlay Berlin Heidelberg.

[3] Awang, S. R., Aripin, R., Rafia, M. H., Ahmad, T. (2013). The classification of Multiple Intelligences of People with Epilepsy using Fuzzy Inverse Model. Malaysian Journal of Fundamental and Applied Sciences 9 (2), pg 86-92.

[4] Varma, N. P., Syalaja, P. N., George, L., Sarma, P. S., Radhakrishnan, K. (2007). Employment concerns of people with epilepsy in Kerala, south India. Epilepsy and Behaviour. 10, 250254.

[5] Gardner, H. (1983). Frames of Mind: The Theory of Multiple Intelligences. New York: Basic Books.

[6] Lim, S. K., Wo, S. W., Wong, M. H., Tan, C. T. (2013). Impact of epilepsy on employment in Malaysia. Epilepsy \&Behaviour. 27. $130-134$.
[7] Smeets, V. M. J., Lierop, B. A. G., Vanhoutvin, J. P. G., Aldenkamp, A. P., Nijhuis, F. J. N. (2007). Epilepsy and Employment: Literature Review. Epilepsy and Behaviour. 10, 354362.

[8] Awang, S. R. (2012). Intelligence Classification and Fuzzy Optimization Model of People with Epilepsy. PhD Thesis, Universiti Teknologi MARA, Malaysia.

[9] Awang, S. R. (2008). Ability Test in Epilepsy Malaysia Patent No 129396. Universiti Teknologi Malaysia.

[10] Park and Hyeoun-Ae (2013). An Introduction to Logistic Regression: From Basic Concepts to Interpretation with Particular Attention to Nursing Domain. J Korean Acad Nurs. Volume 43 (No 2), $154-164$.

[11] Norusis, M. J. (2005). Statistical Procedures Companion. Upper Saddle River: Prentice Hall Inc.

[12] Pallant, J. (2010). SPSS Survival Manual. (4th edn). Australia: Allen \& Unwin Book Publishers. 